Original Article

\title{
FORMULATION, EVALUATION AND OPTIMIZATION OF SUSTAINED-RELEASE DRUG DELIVERY SYSTEM OF CISAPRIDE TABLET
}

\author{
DARSHIT RAM1* ${ }^{*}$, HIMANSHU PANKHANIYA ${ }^{2}$ \\ 1,2*Noble Pharmacy College, Junagadh, 362001, Gujarat, India \\ Email: dramahir@gmail.com
}

Received: 15 Apr 2021, Revised and Accepted: 05 Jul 2021

\begin{abstract}
Objective: Cisapride is a novel prokinetic agent is best candidate for GERD. Cisapride 20 mg can be given thrice in a day given along with Proton pump inhibitor. By developing the sustain release formulation of Cisapride, the frequency of both drug can be reduce to once only to obtain good therapeutic response.

Methods: Cisapride SR Tablets were prepared by direct compression technique with HPMC K4M and HPMC K100M polymers. Followed by various evaluation tests including in vitro disintegration and dissolution, the formulation was optimized by $3^{2}$ full factorial designs with drug release kinetic analysis, compatibility studies (FTIR) and stability studies.

Results: Results of Preformulation studies of the Cisapride indicate that it has poor flow property and compressibility property. To improve the flow and compressibility property, it was beneficial to use the directly compressible grade components in the formulation of tablet. Results of DSC study shown that there is no change in drug's melting peak after the preparation of tablet. Hydrophilic matrix of HPMC K4M and HPMC K100M in combination sustained the Cisapride release effectively for more than 12h. The result indicates that the combination of HPMCK4M and HPMCK100M can be successfully, On the basis of the preliminary trials in the present study a32 full factorial design was employed to study the effect of independent variables, i.e. concentration of HPMCK4M(X1) and concentration of HPMCK100M(X2)on dependent variables like\% drug release Q2, Q6 and Q10. Drug release is also dependent on the size of matrix tablets so, size and surface area was kept constant. Factorial batches F018, F019, F020, and F021 give the f2 value 75-100. Factorial batch F019 gives the highest $\mathrm{f} 2$ value 86.04 and also all the hour's drug release was within the specified limits.
\end{abstract}

Conclusion: The prepared formulation of Cisapride sustains release matrix tablet was stable and effective in treatment.

Keywords: Cisapride, HPMCK100M, Pregelatinize, HPMCK4M

(C) 2021 The Authors. Published by Innovare Academic Sciences Pvt Ltd. This is an open access article under the CC BY license (https://creativecommons.org/licenses/by/4.0/)

DOI: https://dx.doi.org/10.22159/ijpps.2021v13i9.41799. Journal homepage: https://innovareacademics.in/journals/index.php/ijpps.

\section{INTRODUCTION}

Gastroesophageal reflux disease (GERD) is one of the most prevalent upper gastrointestinal disorders in clinical practice. GERD is a chronic disease with relapsing symptoms, and lifelong treatment is required in $25 \%$ to $50 \%$ of patients. The cause of GERD is unknown. The Pathophysiology involves contact of the esophagus with noxious substances in refluxed gastric juice. Everyone experiences episodes of GERD, however, and a cornerstone for the development of GERD is that the contact time between noxious substances in gastric juice with the esophagus must be of sufficient duration to result in damage to the epithelium [1]. Sufficient duration to cause GERD can occur in one of two general ways: first, when contact time between epithelium and gastric contents is so prolonged that the noxious agents in gastric juice overwhelm an otherwise healthy esophageal epithelium and second when contact time between epithelium and gastric contents is essentially normal, yet still adequate to produce damage because of the greater potency to the refluxate or presence of defects thins the epithelium [2].

There are two forms of presentation: in children and in adults. In the first case, the symptoms appear during the first months of life and improve up to $12-24$ mo in $80 \%$ of the cases. Since the 1980 s, there have been major advancements in the medical management of gastroesophageal reflux disease (GERD) [3]. The most successful therapies have increased acid secretion and volume with $\mathrm{H} 2$ receptor antagonists and especially proton-pump inhibitors. Sucralfate, a mucosal protector, had minimal effect on the treatment of GERD except in the rare patient with severe ulcerative esophagitis. Despite GERD being considered motility disorder, such promotility drugs as bethanechol, metoclopramide, and cisapride have had marginal efficacy in treating GERD patients except in patients with no erosive disease or dyspepsia with associated delayed gastric emptying [4]. Through various mechanisms, these drugs were reported to increase lower esophageal sphincter (LES) pressure and improve acid clearance, but in reality, they did little in patients with more severe disease other than improving gastric emptying. None of these promotility agents had an apparent effect on the major motor mechanism underlying reflux episodes, transient lower esophageal sphincter relaxations (TLESRs) [4].

The diagnosis of gastroparesis may be confirmed by demonstrating gastric emptying delay during a 4-hour scintigraphic study [5]. Conventional drug therapy requires periodic doses of therapeutic agents. These agents are formulated to produce maximum stability, activity and bioavailability. For most drugs, conventional methods of drug administration are effective, but some drugs are unstable or toxic and have narrow therapeutic ranges. Some drugs also possess solubility problems. In such cases, a method of continuous administration of therapeutic agent is desirable to maintain fixed plasma levels [6]. To overcome these problems, controlled drug delivery systems were introduced three decades ago. These delivery systems have a number of advantages over traditional systems, such as improved efficiency, reduced toxicity, and improved patient convenience. The main goal of controlled drug delivery systems is to improve the effectiveness of drug therapies [7].

In the present study, objectives are to formulate stable, effective and optimum sustained release dosage form using hydrogel polymers, to study the effect of different excipients in the formulation, to evaluate the prepared sustained release dosage forms and to perform the stability studies.

\section{MATERIALS AND METHODS}

\section{Materials}

Cisapride Hydrochloride (Cadila Healthcare ltd, Ahmedabad), Microcrystalline Cellulose ( $\mathrm{pH}$ 102) (FMC Biopolymer), Hydroxy 
propyl methyl cellulose K4M (Dow Chemicals, India), Hydroxy propyl methyl cellulose K100M (Dow Chemicals, India), Pregelatinize Starch (Colorcon Asia Pvt. Ltd., Mumbai, India), Colloidal silicon dioxide (Cabot sanmar Ltd), Magnesium Stearate (Amishi drugs and Chemicals).

\section{Instrument}

Electronic weighing balance (Mettler Toledo PG 403-S, Denver Instrument), Cage Blender (Shaan Engineering Pvt. Ltd., Ahmedabad, India), Bulk Density measurement apparatus (Electrolab, ETD1020), "D" Tooling 8 Station Tablet compression machine (Cadmach machinery Co., Pvt. Ltd., Ahmedabad, India), Tablet Hardness Tester (Monsanto hardness tester, Mumbai), Friability test apparatus (Electrolab, Mumbai), Vernier caliper (Mitutoyo, Mumbai), Dissolution Test Apparatus (Electrolab, TDT-06T, Mumbai, India), UV Spectrophotometer (UV-1700 Double beam Spectrophotometer, Shimadzu Kyoto, Japan).

\section{Characterization of cisapride}

Description: A white to off white crystalline powder.

Identification: The Infra-Red absorption spectrum of the finely ground sample in $\mathrm{KBr}$ dispersion compressed into a disc should exhibit maxima only at the same wavelengths as that of a similar preparation of working standard [8].

\section{Selection and justification of excipients}

Diluents: In view of the low or medium dose of drug it is essential to add bulking agents or diluents to increase the weight of the tablet. Microcrystalline Cellulose (Avicel) was selected as diluents. Microcrystalline cellulose in combination as diluents gives better flowability i.e. both used as diluent in this SR preparation $[9,10]$.

Matrix-forming polymers: HPMC which is most widely used matrix-forming polymer because of its excellent compatibility, multifunctional property and cost effective, HPMC K4M and HPMC K100M (10 to $80 \%$ ) [11].

Lubricants: Magnesium Stearate $(0.25-4 \%)$ and Colloidal silicon dioxide $(0.25-3 \%)$ are widely used as lubricating agent. [12].

\section{Preformulation study}

Solubility: Freely soluble in water, $0.1 \mathrm{~N} \mathrm{HCl}, \mathrm{pH} 4.5$ Acetate buffer and in methanol, Soluble in $\mathrm{pH} 6.8$ Acetate buffer [13].

Bulk density $=$ Weight of powder/Bulk volume

Tapped bulk density $=$ Weight of powder/Tapped volume

$$
\begin{gathered}
\text { Carr's Index }(\%)=\frac{[(\mathrm{TD}-\mathrm{BD}) \times 100]}{\mathrm{TD}} \\
\text { Hausner's Ratio }=\frac{\mathrm{TD}}{\mathrm{BD}}
\end{gathered}
$$

\section{Angle of repose}

The diameter of the powder cone was measured and angle of repose was calculated using the equation $\tan \frac{1}{2}=h / r$. Where, $h$ and $r$ are the height and radius of the powder cone, respectively [14].

\section{Drug excipients compatibility study}

API and excipients were been thoroughly mixed in predetermined ratio given in below table and passed through the $40 \#$ sieve. The blend was to be filled in transparent glass vials and were closed with gray colored rubber stoppers and further sealed with aluminum seal and charged in to stress condition at above condition. Similarly, API should also be kept at all conditions as for the samples. Samples were withdrawn for analysis within two day of sampling date as per the compatibility study plan. Physical observation should be done at every week up to 1 mo and DSC studies were carried out to determine the compatibility of excipients with the drug [15].

\section{Analytical method development}

Calibration curve of Cisapride Hydrochloride: Calibration curve for Cisapride hydrochloride was taken in $0.1 \mathrm{~N} \mathrm{HCl} \mathrm{[16].}$
Preparation of reagents: (i) $0.1 \mathrm{~N}$ Hydrochloric acid $(\mathrm{pH}=1.2): 112$, $8.5 \mathrm{ml}$ of concentrated Hydrochloric acid was taken and added to $1000 \mathrm{ml}$ of water and measured the $\mathrm{pH}$ of the solution. (ii) Standard (Stock) solution: Cisapride hydrochloride $100 \mathrm{mg}$ was dissolved in $0.1 \mathrm{~N} \mathrm{HCl}$ and volume was made up to $1000 \mathrm{ml}$ in $100 \mathrm{ml}$ volumetric flask. This stock solution was $100 \mathrm{mcg} / \mathrm{ml}$. This Stock solution was diluted with $0.1 \mathrm{~N} \mathrm{HCl}$ to make the concentration of 5, 10, 15, 20, 25 $\mathrm{mcg} / \mathrm{ml}$. Absorbance of each solution was measured at $258 \mathrm{~nm}$ using Shimadzu UV/Visible double beam spectrophotometer by using $0.1 \mathrm{~N}$ hcl $[17,18]$.

\section{Formulation of preliminary trials}

Trial batches with HPMC K4M and HPMC K100M

Formula method of Preparation of Cisapride SR Tablet

\section{Method}

Cisapride SR Tablets were prepared by direct compression technique. Sifting: Drug was passed through 40\# sieve. HPMC K4M and HPMC K100M were passed through $30 \#$ sieve. All the other ingredients were passed through 40 \# sieve accept Mg Stearate. Mg Stearate was passed through 60\# sieve [19, 20].

\section{Mixing and lubrication}

Cisapride, MCC Avicel pH102 was mixed in a blender for 10 min. at 18 RPM. Add polymer and colloidal silicon dioxide into the above mixture and again mix for $10 \mathrm{~min}$. at $18 \mathrm{RPM}$. Add Mg Stearate into above mixture and mixed it for $3 \mathrm{~min}$. at 18 RPM.

\section{Evaluation}

\section{Uniformity of weight}

The USP-XXIX weight variation test was carry out by weighing 20 tablets individually, calculating the average weight, comparing the individual tablet weight to average weight. The tablet meets USPXXIX test if no tablet differs by more than two times of percentage deviation USP-XXIX Standards for Weight Variation Test [21, 22].

\section{Thickness}

Thickness of tablets was determining using a venire caliper. Three tablets were evaluated and an average value was calculated. The thickness was measure in $\mathrm{mm}$.

\section{Hardness test}

Hardness was measure using Pfizer hardness tester. For each batch ten tablets was test. The force required to break the tablet is recorded. The hardness of tablets of each batch was measured in $\mathrm{kg} / \mathrm{cm}^{2}$.

\section{Friability test}

Twenty tablets was weighed and placed in the Roche friabilator and apparatus was rotate at $25 \mathrm{rpm}$ for 6 min. After revolutions the tablets was deducted and weighed again. The percentage friability was measured using the formula.

\section{Uniformity of content}

Amount of the powder equivalent to $10 \mathrm{mg}$ of Cisapride and was dissolved in $100 \mathrm{ml}$ of $0.1 \mathrm{~N} \mathrm{HCl} \mathrm{pH} \mathrm{1.2,} \mathrm{filtered,} \mathrm{diluted} \mathrm{suitably} \mathrm{and}$ analyzed for drug content at $227 \mathrm{~nm}$ using UV-spectrophotometer.

\section{In vitro disintegration time}

In vitro disintegration time of three tablets was determined by using digital tablet disintegration apparatus. In vitro disintegration test was carried out at $37 \pm 20 \mathrm{C}$ in $900 \mathrm{ml} 0.1 \mathrm{~N} \mathrm{HCL} \mathrm{pH} 6.8$ [23].

\section{In vitro dissolution study}

In vitro dissolution study of Cisapride was performed using USP Type II dissolution apparatus (Paddle type) at $37 \pm 0.5{ }^{\circ} \mathrm{C}$ and a paddle speed of $75 \mathrm{rpm}, 900 \mathrm{ml}$ of $0.1 \mathrm{~N}$ HCL pH 6.8 was utilized as dissolution medium $[24,25]$. The temperature of the medium was maintained at $37 \pm 0.5^{\circ} \mathrm{C}$. Aliquot of dissolution medium $(5 \mathrm{ml})$ was withdrawn at specific time intervals $(10,20,30,45 \mathrm{~min}$.) and filtered 
each with $(0.45 \mu \mathrm{m})$ whatman filter paper. Equal amount of fresh dissolution medium was replaced immediately after each withdrawal. The amounts of drugs present in each sample were determined by a UV-Visible spectrophotometer after Cisapride. Dissolution studies were performed in triplicate $(n=3)$, and calculated mean values of cumulative drug release were used to plot the release curves [26, 27].

Formulation and optimization of sustained-release matrix tablets by using $3^{2}$ full factorial designs

It is desirable to develop an acceptable pharmaceutical formulation in the shortest possible time using the minimum number of manhours and raw materials. A statistical model incorporating interactive and polynomial terms was used to evaluate the responses [28]. A $3^{2}$ randomized full factorial design was utilized in the present study. In this design, two factors were evaluated, each at three levels and experimental trials were carried out at all nine possible combinations. The factors were selected based on a preliminary study [29]. The concentration of HPMC K4M (X1) and concentration of HPMC K100M (X2) were selected as independent variables. The \% drug release at 2, 6 and 8th hours were Q2, Q6 and Q8 respectively selected as dependent variables [30, 31].

\section{Comparison of dissolution profiles by statistical analysis}

The similarity factor (f2) was defined by CDER, FDA and EMEA as the "logarithmic reciprocal square root transformation of one plus the mean squared difference in percent dissolved between the test and the reference products". Moore and Flanner give the modelindependent mathematical approach for calculating a similarity factor f2 for comparison between dissolution profiles of different samples. The similarity factor (f2) given by SUPAC guidelines for modified release dosage form was used as a basis to compare dissolution profile. The dissolution profiles of products were compared using f2. The similarity factor is calculated [32].

Drug release kinetic analysis by using different release model of Cisapride $\mathrm{HCl}$ sustained release matrix tablet

To know the mechanism of drug release from these formulations, the data were treated according to first-order (log cumulative percentage of drug remaining vs. time), Higuchi's118 (cumulative percentage of drug released vs. square root of time), and Korsmeyer et al.'s119 (log cumulative percentage of drug released vs. log time) equations along with zero-order (cumulative amount of drug released vs. time) pattern the results shown below. The in vitro release profiles of the drug from all the formulations could be best expressed by Higuchi's equation, as the plots showed high linearity ( $\mathrm{R} 2=0.9898$, table 5.33). To confirm the diffusion mechanism, the data were fit into Korsmeyer-Peppas's equation. The formulations F019 showed good linearity (R2: 0.9942), with slope (n) values ranging from 0.665, indicating that diffusion is the dominant mechanism of drug release with these formulations [33]. This $n$ value, however, appears to indicate a coupling of diffusion and erosion mechanisms so-called anomalous diffusion. The relative complexity of this formulation and its components may indicate that the drug release is controlled by more than one process. From the above data analysis by using the different model the Korsemeyer model was a good fit with a linearity value 0.9942 [34].

\section{Stability study}

Formulation was placed for stability study at $40^{\circ} \mathrm{C}$ and $75 \% \mathrm{RH}$ for 1 mo. Sample was collected at every week interval and evaluated for dissolution in $0.1 \mathrm{~N} \mathrm{HCl}$, USP-II paddle apparatus, $50 \mathrm{rpm}$. f2 value was applied to stability study to show the effect of storage on in vitro drug release of the formulation [35].

\section{RESULTS AND DISCUSSION}

\section{Identification of drug}

\section{Melting point}

The observed melting point of Cisapride was $110-113{ }^{\circ} \mathrm{C}$. Melting point of Cisapride was found to be in the range of $113^{\circ} \mathrm{C}$ as reported in the literature, thus indicating the purity of the drug sample.

\section{Infrared spectroscopy of drug}

Observed characteristics were $\mathrm{N}-\mathrm{H}$ stretching at $3400 \mathrm{~cm}^{1}, \mathrm{CH}$ alkane stretching at $2926 \mathrm{~cm}^{1}, \mathrm{CO}-\mathrm{NH}$ stretching $(\mathrm{C}=0)$ at $1640 \mathrm{~cm}^{1}$, $\mathrm{NH}$ bending at $1425 \mathrm{~cm}^{1}$ and $\mathrm{CN}$ aromatic amine at1243 $\mathrm{cm}^{1}$ as shown in fig. 1.

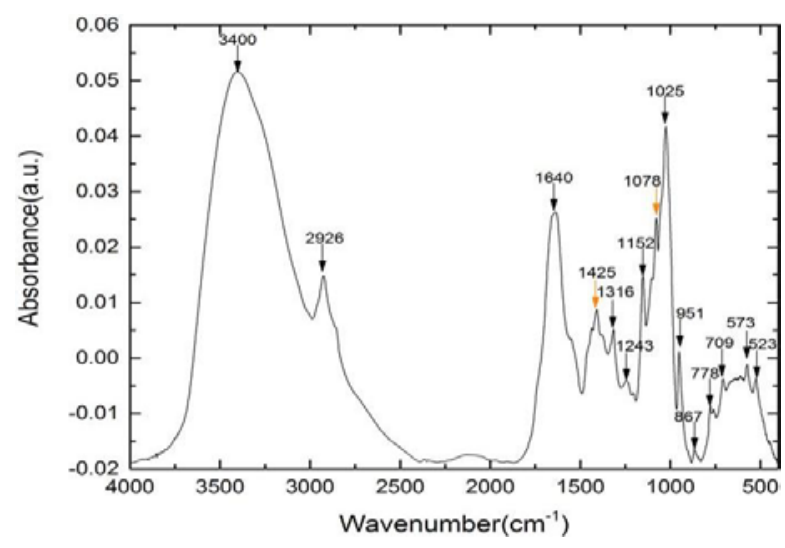

Fig. 1: FTIR of cisapride

\section{Infrared spectroscopy drug and excipient}

IR spectrum of, physical mixture of Cisapride+MCC+HPMC K100M+Pregelatinize Starch and Drug+Colloidal Siliconn Dioxide+MgStearate are shown in fig. 2 and 3. From IR spectra of drug and physical mixture, no significant change in peak pattern was observed. Hence, it was concluded that absence of drug excipients interaction and drug was compatible with excipients used in the present work.

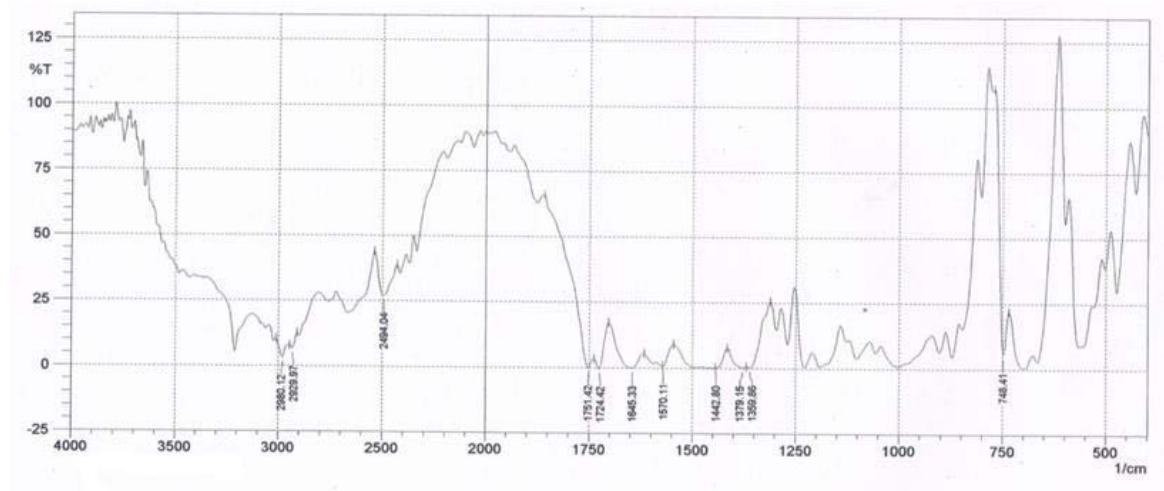

Fig. 2: Drug+MCC+HPMC K100M+pregelatinize starch 


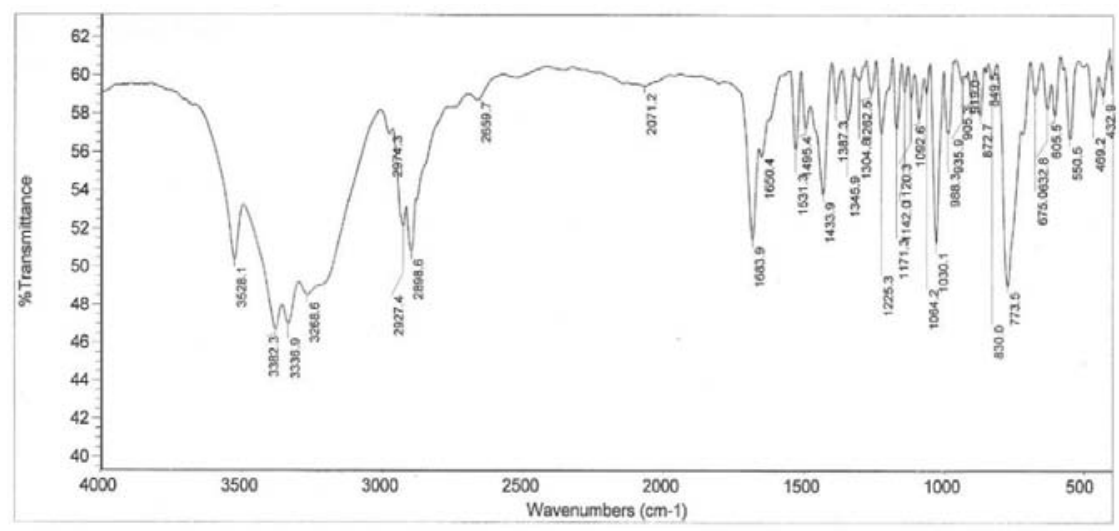

Fig. 3: Drug+colloidal siliconn dioxide+Mg-stearate

\section{Drug excipients compatibility study}

Drug excipients compatibility study was done with Drug: MCC, Drug: Pregelatinize Starch, Drug: Methocel K100M at (1:1) ratio and Drug: Colloidal Silicon Dioxide, Drug: Mg Stearate at (1:0.25) followed by Drug+MCC+Pregelatinize Starch+HPMC K100M+Colloidal silicon Dioxide+Mg-Stearate propositional mixture at $25{ }^{\circ} \mathrm{C}{ }^{\circ} \pm 2$ ${ }^{\circ} \mathrm{C} / 60 \% \mathrm{RH} \pm 5 \% \mathrm{RH}$ and $40{ }^{\circ} \mathrm{C} \pm 2{ }^{\circ} \mathrm{C} / 75 \% \mathrm{RH} \pm 5 \% \mathrm{RH}$ for $4 \mathrm{w}$ duration.

\section{DSC study}

From the DSC Study results shown with physical observation, it was concluded that there was no significant Drug-Excipient interaction was observed. The results of DSC study shown that there is no change in drug's melting peak after the preparation of tablet. So we can conclude that drug and other Excipients are compatible which each other [36].

\section{Preformulation study results}

From the Results of Preformulation studies of the API, It was concluded that Cisapride has poor flow property and compressibility property. So, to improve the flow and compressibility property, it was beneficial to use the directly compressible grade components in the formulation of the tablet [37].

\section{Analytical method development}

\section{UV spectroscopy}

As shown in table 1 , Stock solution $(1 \mathrm{mg} / \mathrm{ml})$ of drug was prepared in water. This solution was appropriately diluted with water to obtain a concentration of $200 \mu \mathrm{g} / \mathrm{ml}$. The solution was kept in a silica cuvette $10 \mathrm{~mm}$. The UV spectrum was recorded in the range 200-400 nm on Shimadzu 2501 PC double beam spectrophotometer at $1 \mathrm{~nm}$, slit width [38]

Table 1: Preformulation study of cisapride

\begin{tabular}{llllll}
\hline Drug & Angle of repose $\left({ }^{\circ}\right.$ ) & Loose bulk density $(\mathbf{g} / \mathbf{m l})$ & Tapped bulk density $(\mathrm{g} / \mathbf{m l})$ & Carr's index (\%) & Hausner's ratio \\
\hline Cisapride & $27.34 \pm 0.52$ & $0.375 \pm 0.05$ & $0.516 \pm 0.03$ & $27.32 \pm 0.4$ & $1.37 \pm 0.04$ \\
\hline
\end{tabular}

$\mathrm{n}=3$, mean $\pm \mathrm{SD}$

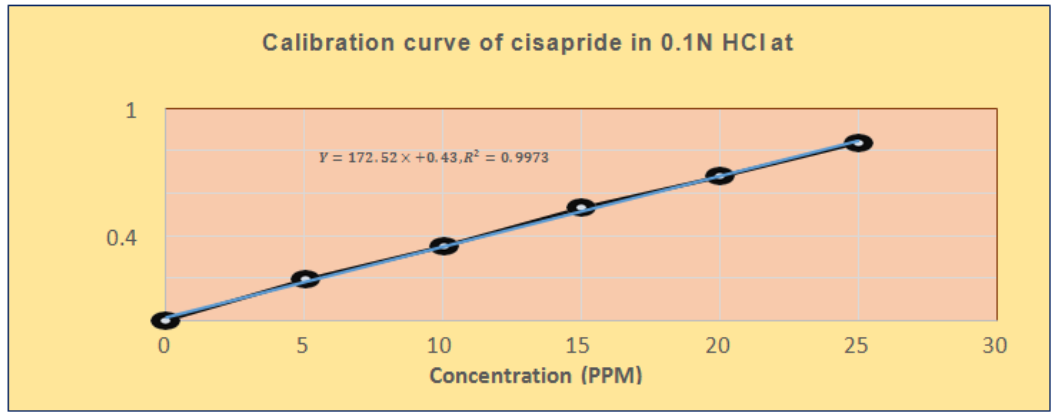

Fig. 4: Calibration curve of cisapridein $0.1 \mathrm{~N} \mathrm{HCl}$

Table 2: Absorbance at different concentrations of cisapride

\begin{tabular}{|c|c|c|c|c|c|}
\hline \multirow[t]{2}{*}{ S. No. } & \multirow[t]{2}{*}{ Concentration (mcg/ml) } & \multicolumn{3}{|c|}{ Absorbance } & \multirow[t]{2}{*}{ Avg. Absorbance \pm SD } \\
\hline & & $\mathbf{A}_{1}$ & $\mathbf{A}_{2}$ & $\mathbf{A}_{3}$ & \\
\hline 1 & 0 & 0 & 0 & 0 & 0 \\
\hline 2 & 5 & 0.198 & 0.186 & 0.189 & $0.191 \pm 0.003$ \\
\hline 3 & 10 & 0.351 & 0.359 & 0.352 & $0.354 \pm 0.002$ \\
\hline 4 & 15 & 0.534 & 0.530 & 0.526 & $0.530 \pm 0.005$ \\
\hline 5 & 20 & 0.688 & 0.687 & 0.686 & $0.687 \pm 0.003$ \\
\hline 6 & 25 & 0.843 & 0.851 & 0.850 & $0.848 \pm 0.005$ \\
\hline
\end{tabular}

amean $\pm \mathrm{SD}, \mathrm{n}=3$ 


\section{Formulation of preliminary trials}

\section{Trial batches with HPMC K4M and HPMC K100M}

Table 2: Formula of trial batches F001 to F005

\begin{tabular}{|c|c|c|c|c|c|}
\hline Trial & F001 & F002 & F003 & F004 & F005 \\
\hline Cisapride & 20.00 & 20.00 & 20.00 & 20.00 & 20.00 \\
\hline MCC(Avicel PH 102) & 35.00 & 25.00 & 35.00 & 25.00 & 30.00 \\
\hline HPMC K4M & 30.00 & 40.00 & $\ldots$ & $\ldots$ & $\ldots$ \\
\hline HPMC K100M & $\ldots$ & $\ldots$ & 30.00 & 40.00 & 35.00 \\
\hline Colloidal SiliconDioxide & 6.00 & 6.00 & 6.00 & 6.00 & 6.00 \\
\hline MagnesiumStearate & 4.00 & 4.00 & 4.00 & 4.00 & 4.00 \\
\hline Talc & 5.00 & 5.00 & 5.00 & 5.00 & 5.00 \\
\hline Total & 100.00 & 100.00 & 100.00 & 100.00 & 100.00 \\
\hline
\end{tabular}

MCC: Microcrystalline cellulose, HPMC: hydroxypropyl methylcellulose

The results of angle of repose and compressibility index ranged from $23.31 \pm 0.42$ to $25.14 \pm 0.32$ and $11.83 \pm 0.22$ to $15.28 \pm 0.40$, respectively. The results of Hausner's ratio and blend uniformity ranged from $1.13 \pm 0.05$ to $1.18 \pm 0.04$ and $98.23 \pm 0.15$ to $99.21 \pm 0.39$, respectively [1]. The results of the angle of repose $(<30)$ indicate good flow properties of the powder. This was further supported by lower compressibility index values. Generally, compressibility index values up to $15 \%$ results in good to excellent flow properties.

\section{Evaluation of tablets}

Hardness of the prepared tablets was found in the range of 6-8 kP. All the tablet formulations showed acceptable pharmaco technical properties and complied with the in-house specifications for weight variation, drug content, hardness, and friability.

\section{In vitro release study}

The results of in vitro dissolution study of trial batches F001 to F005 which was taken singal polymer like HPMC K4M and HPMC K100M. From the results as shown in fig. 5, concluded that by using single polymer like HPMC K4M and HPMC K100M, release profile was not desirable. However, among these formulations, F004 and F005 were selected for further development because they shown comparatively less deviation from the targeted release profile. So, further study was planned by using some release retardant polymer like Ethyl cellulose and Pregelatinize starch in different concentrations [40].

Trials with ethyl cellulose and pregelatinize starch in combination with HPMC K100M

The results with release retardant polymer in combination with HPMC K100M indicate that the formulations still need modification to get desired release profile. Based on this study, it was proposed to use the combination of both water-soluble matrix-forming polymer HPMC K4M and HPMC K100M in proper concentration.

\section{Trials with the combination of HPMC K4M and HPMC K100M}

Hydrophilic matrix of HPMC K4M and HPMC K100M in combination sustained the Cisapride release effectively for more than $12 \mathrm{~h}$. From the result, it concluded that the combination of HPMC K4M and HPMC $\mathrm{K} 100 \mathrm{M}$ can be successfully utilized to create desire release profile similar to the targeted release profile in further study. On the basis of the preliminary trials in the present investigation, a $3^{2}$ full factorial design was applied to study the effect of independent variables, i.e. concentration of HPMC K4M (X1) and concentration of HPMC K100M (X2) on dependent variables like \%drug release Q2, Q6 and Q10.

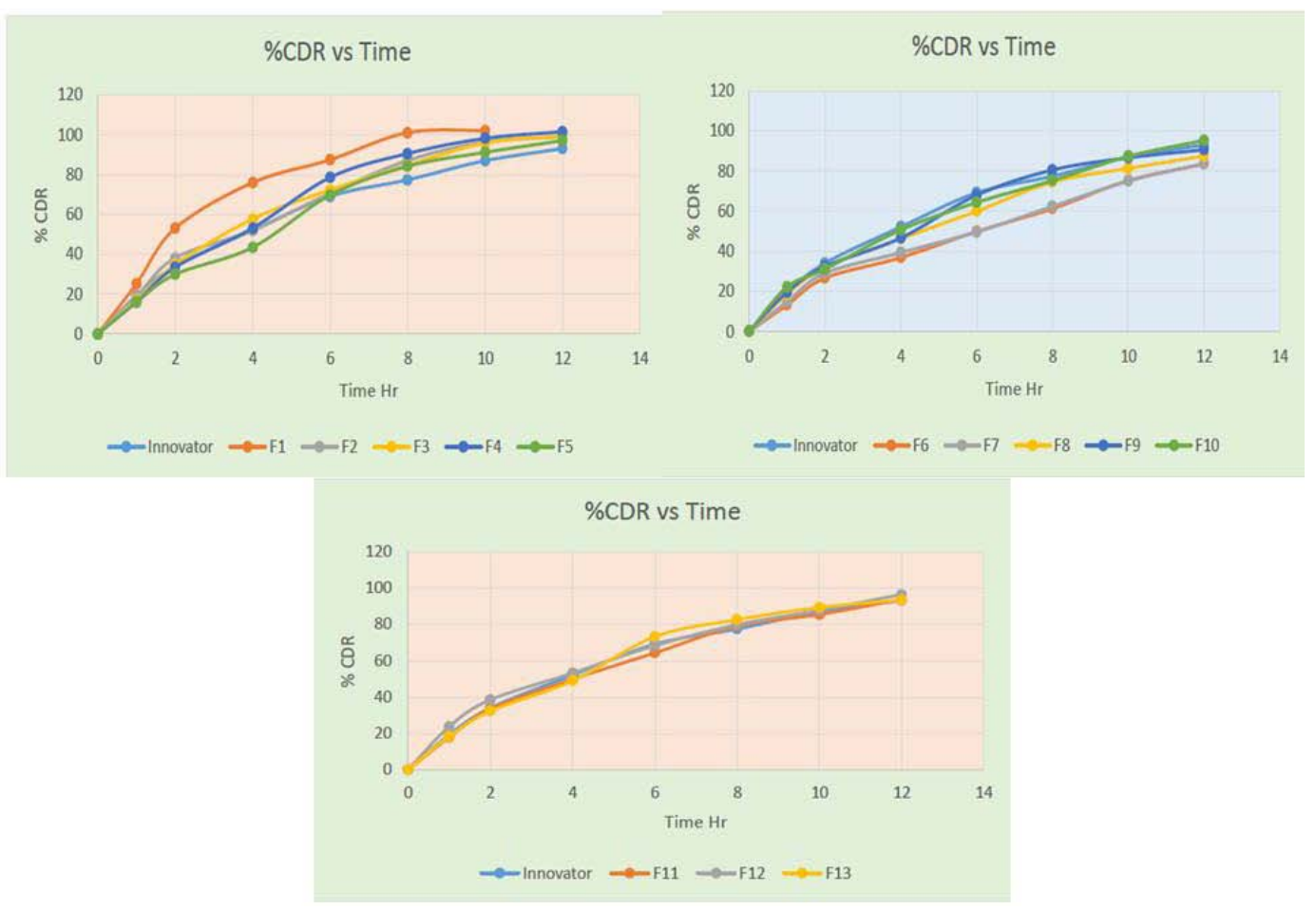

Fig. 5: Comparative dissolution profile of Trial F01 to F013 and Innovator 
Formulation and optimization of sustained-release matrix tablets by using $3^{2}$ full factorial designs: $3^{2}$ full factorial design layout of Cisapride sustained release matrix tablet of selected formulations.

Table 3: Formula of factorial batches

\begin{tabular}{|c|c|c|c|c|c|c|c|c|c|}
\hline Trial & F014 & F015 & F016 & F017 & F018 & F019 & F020 & F021 & F022 \\
\hline Cisapride & 20.00 & 20.00 & 20.00 & 20.00 & 20.00 & 20.00 & 20.00 & 20.00 & 20.00 \\
\hline MCC (Avicel PH 102) & 30.00 & 25.00 & 20.00 & 25.00 & 20.00 & 15.00 & 20.00 & 15.00 & 10.00 \\
\hline HPMC K4M DC Grade & 15.00 & 15.00 & 15.00 & 20.00 & 20.00 & 20.00 & 25.00 & 25.00 & 25.00 \\
\hline HPMC K100M DC Grade & 20.00 & 25.00 & 30.00 & 20.00 & 25.00 & 30.00 & 20.00 & 25.00 & 30.00 \\
\hline Colloidal silicon dioxide & 6.00 & 6.00 & 6.00 & 6.00 & 6.00 & 6.00 & 6.00 & 6.00 & 6.00 \\
\hline Magnesium stearate & 4.00 & 4.00 & 4.00 & 4.00 & 4.00 & 4.00 & 4.00 & 4.00 & 4.00 \\
\hline Talc & 5.00 & 5.00 & 5.00 & 5.00 & 5.00 & 5.00 & 5.00 & 5.00 & 5.00 \\
\hline Total & 100 & 100 & 100 & 100 & 100 & 100 & 100 & 100 & 100 \\
\hline
\end{tabular}

MCC: Microcrystalline cellulose, HPMC: hydroxypropyl methylcellulose

\section{In vitro drug release}

The result of regression analysis showed that all the co-efficient bear a negative sign, which indicates that by increasing the concentration of both the polymers the drug release was sustained. Drug release at 2nd hr (Q2) gives a correlation co-efficient 0.9907.

The P-value for variable X1 and X2 were 0.0006 and 0.002 respectively $(\mathrm{P}<0.05)$, it indicate that both variable shown significant effect on drug release and combination co-efficient was negative but the $P$ value was not less than 0.05 , which indicates that combination of an independent variable did not show significant effect at $2 \mathrm{nd}$ h release

$\mathrm{Q} 2=37.644-5.417 \mathrm{X} 1-3.25 \mathrm{X} 2-0.7 \mathrm{X} 1 \mathrm{X} 2-2.017 \mathrm{X} 2-0.817 \mathrm{X} 2$

Drug release at $8 \mathrm{~h}(\mathrm{Q} 8)$ has less linearity compared to Q2 with a correlation coefficient 0.9849 . The P-value for variable X1 and X2 were 0.013 and $0.007(\mathrm{P}<0.05)$, it indicate that both variable has a significant effect on the drug release at $6 \mathrm{~h}$. and the combination coefficient was negative but the P-value was not less than 0.05 so, we say that the combination of independent variable was not giving the significant effect at $6 \mathrm{~h}$ release. The co-efficient of X1 and X2 were negative indicate that when the concentration of both the variable increase than drug release was decreased.

$$
\mathrm{Q} 8=72.367-8.05 \mathrm{X} 1-4.4 \mathrm{X} 2-2.275 \mathrm{X} 1 \mathrm{X} 2-3.75 \mathrm{X} 12-0.11 \mathrm{X} 2
$$

Drug release at $10 \mathrm{~h}(\mathrm{Q} 10)$ has the $\mathrm{P}$-value for variable $\mathrm{X} 1, \mathrm{X} 2$ and $\mathrm{X} 1 \mathrm{X} 2$ were $0.002,0.024,0.035$ respectively $(\mathrm{P}<0.05)$, it indicate that both variable has a significant effect and also the combination of variable has a significant effect on drug release at $10 \mathrm{~h}$. The coefficient of X1 and X2 were negative indicate that when the concentration of both the variable increase than drug release was decreased.

$$
\mathrm{Q} 12=90.844-5.8 \mathrm{X} 1-2.633 \mathrm{X} 2-2.8 \mathrm{X} 1 \mathrm{X} 2-0.26 \mathrm{X} 12-2.467 \mathrm{X} 2
$$

The Q2, Q8, and Q10 for all the batches F014 to F022 varied from 43.2 $\%$ to $25.1 \%, 79.4 \%$ to $52.9 \%$, and $94.3 \%$ to $75.8 \%$ with correlation coefficient as $0.9907,0.9849$ and 0.9760 respectively. The dissolution profile of all the formulation batches prepared by using 32 factorial designs was compared by similarity factor f2 value. Factorial batches F018, F019, F020 and F021 give the f2 value 75.85, 86.04, 82.81, 74.71 respectively. In factorial batch F018 the drug release obtained was $57.1 \%, 70.8 \%$ and $80.1 \%$ at $4 \mathrm{~h}, 6 \mathrm{~h}$, and $8 \mathrm{~h}$, respectively, was faster than the targeted release profile. In trial batch F020, f2

Value was above 75 but 4 th hr release was outside the specified range. Trial batch F021 also has the f2 value nearer 75 , but $4 \mathrm{~h}$ release was slower than we required. Trial batch F019 the highest f2 value 86.04 was obtained and also, all the hour's drug release was within the specified range. Based on the f2 value and targeted release profile, the suggested optimized batch was F019.

\section{CONCLUSION}

Factorial batches F018, F019, F020, and F021 give the f2 value 75100. Factorial batch F019 gives the highest f2 value 86.04 and also all the hour's drug release was within the specified range. Based on the f2 value and targeted release profile, the optimized batch was F019. The co-efficient of X1 and X2 were negative indicate that when the concentration of both the variables increase than drug release was decrease. From the result of $3^{2}$ full factorial design and regression analysis for Cisapride Sustained release matrix tablet, it was concluded that factorial batch F019 taken with the combination of $7.5 \%$ HPMC K4M and 25\% HPMC K100M give drug release comparable to the targeted release profile with f2 value 86.04 .

In the present study, to check the reproducibility, batch was taken with larger batch size and carried out accelerated stability study. From the result, it concluded that the reproducible batch taken with $7.5 \%$ HPMC K4M and 25\% HPMC K100M has good reproducibility. The result of regression analysis showed that all the co-efficient bear a negative sign, which indicates that by increasing the concentration of both the polymers the drug release was sustained. The drug release was followed the Korsemeyer model and which indicate a coupling of diffusion and erosion mechanisms, so-called anomalous diffusion. From the stability result we said that there was no change in the formulation after 1 mo accelerated stability study. The prepared formulation of the Cisapride sustain release matrix tablet was stable.

\section{ACKNOWLEDGMENT}

We are thankful to Noble Pharmacy College, Junagadh for kind of support during the entire study

\section{DECLARATIONS}

Availability of data and materials: The datasets were used and analyzed during the current study available from the corresponding author on reasonable request.

\section{ETHICAL APPROVAL}

This article does not contain any studies with human participants or animals performed by any of the authors.

\section{AUTHORS' CONTRIBUTIONS}

All authors are contributed equally.

\section{FUNDING}

Nil

\section{CONFLICT OF INTERESTS}

The author declares that they have no conflict of interest.

\section{REFERENCES}

1. Zamir D. Gastroesophageal reflux. Eur J Intern Med 2005;16:391-401.

2. Bravo SA, MC Lamas, CJ Salomon. In vitro studies of diclofenac sodium controlled-release from biopolymeric hydrophilic matrices. J Pharm Pharm Sci 2002;5:213-9.

3. Karakkattu J, R Pr. Etiology for liver diseases in the pediatric population. Asian J Pharm Clin Res 2017;10:91-4. 
4. Manzotti ME, Catalano HN, Serrano FA, Di Stilio G, Koch MF, Guyatt G. Prokinetic drug utility in the treatment of gastroesophageal reflux esophagitis: a systematic review of randomized controlled trials. Open Med 2007;1:e171.

5. Takeda M, Mizutani Y, Yamano M, Tsukamoto K, Suzuki T. Gastric emptying in diabetic gastroparetic dogs: effects of SK951, a novel prokinetic agent. Pharmacology 2001;62:23-8.

6. Hongo $\mathrm{M}$, Okuno $\mathrm{Y}$. Diabetic gastropathy in patients with autonomic neuropathy. Diabetic Med 1993;10:79S-81S.

7. Lee $\mathrm{T}, \mathrm{J}$ Robinson. In remington: the science and practice of pharmacy; Gennaro, Ed. Lippincott Williams and Wilkins: Baltimore 2000;2:903-29.

8. Wiseman LR, Faulds D. Cisapride. Drugs 1994;47:116-52.

9. Kibbe AH. Handbook of pharmaceutical excipients: Amer pharmacists assn; 2000.

10. Moore JW, Flanner HH. Mathematical comparison of dissolution profiles. Pharm Technol 1996;20:64-74.

11. Costa P, Lobo JMS. Modeling and comparison of dissolution profiles. Eur J Pharm Sci 2001;13:123-33.

12. Cooper J, Gunn C. Powder flow and compaction. Tutorial Pharmacy. New Delhi, CBS Publishers and Distributors, India; 1986;10:20-30.

13. Alhamdany AT, Abbas AK. Formulation and in vitro evaluation of amlodipine gastroretentive floating tablets using a combination of hydrophilic and hydrophobic polymers. Int J Appl Pharm 2018;10:119-25.

14. Kovvasu SP, Chowdary K. Formulation development and in vivo evaluation of pioglitazone inclusion complexes: a factorial study. Int J Appl Pharm 2018;10:49-5.

15. Jangde R, Singh D. Compatibility studies of quercetin with pharmaceutical excipients used in the development of novel formulation. Res J Pharm Technol 2014;7:1101.

16. Khan A, Agrawal S. Formulation and evaluation of lumefantrine capsule prepared by using liquisolid technique. Int J Curr Pharm Sci 2018;10:43.

17. Sankalia JM, Sankalia MG, Mashru RC. Drug release and swelling kinetics of directly compressed glipizide sustainedrelease matrices: establishment of level A IVIVC. J Controlled Release 2008;129:49-58.

18. Rodriquez M, Vila Jato JL, Torres D. Design of a new multi particulate system for potential site-specific and controlled drug delivery to the colonic region. J Controlled Release 1998;55:67-77.

19. Vaidya N, N Yak R, Benhar R, Narayanswamy VB. Design and evaluation of controlled release tablets of paroxetine hydrochloride. Int Res J Pharm 2013;4:84-62.

20. Gupta P, Gnanarajan G, Kothiyal P. Floating drug delivery system: a review. Int J Pharm Res Rev 2015;4:37-44.

21. Pawar HA, Dhavale R. Development and evaluation of gastroretentive floating tablets of an antidepressant drug by thermoplastic granulation technique. Beni-Suef University J Basic Appl Sci 2014;3:122-32.

22. Sah SK, Badola A, Mukhopadhyay S. Development and evaluation of tioconazole loaded emulgel. Int J Appl Pharm 2017;9:83-90.

23. Kumar KK, Sasikanth K, Sabareesh M, Dorababu N. Formulation and evaluation of diacerein cream. Asian J Pharm Clin Res 2011;4:93-8.
24. Kikwai L, Babu RJ, Prado R, Kolot A, Armstrong CA, Ansel JC, et al. In vitro and in vivo evaluation of topical formulations of spantide II. AAPS PharmSciTech 2005;6:565-72.

25. Husseini GA, Pitt WG. Micelles and nanoparticles for ultrasonic drug and gene delivery. Adv Drug Delivery Rev 2008;60:113752 .

26. Golla U, Nalla BK, Talla R, Gajam PK, Voore SK. Formulation and in vitro evaluation of gastroretentive drug delivery system of ciprofloxacin hydrochloride. Der Pharm Sin 2011;2:33-9.

27. Pati N, Gupta V, Velivela S, Mayasa V. Comparative study of effect various types of polymers on the extended-release of tapentadol HCl. Int J Pharm Tech 2016;8:12762-75.

28. Biswas M, Gupta RN, Parhi R, Sethi KK, Sahoo SK. Formulation and in vitro evaluation of gastroretentive floating drug delivery system of ritonavir. Turkish J Pharm Sci 2013;10:69-86.

29. Manimaran V, Damodharan N. Development of fast-dissolving tablets of amlodipine besylate by solid dispersion technology using poloxamer 407 and poloxamer 188. Asian J Pharm Clin Res 2017;10:135-41.

30. Choudhari PK, Jain HK, Sharma P, Srivastava B. A novel coprocessed directly compressible release-retarding polymer: in vitro, solid-state and in vivo evaluation. Future J Pharm Sci 2018;4:29-40.

31. Ereira MG, Arruda MAZ. Trends in pre-concentration procedures for metal determination using atomic spectrometry techniques. Microchim Acta 2003;141:115-31.

32. Maheswari PD, Rambhau D, Narasu ML. Microparticlesentrapped micelles: a novel delivery system to improve solubility and dissolution rate of poorly water-soluble valsartan. J Microencapsul 2013;30:805-16.

33. Amelia A, Vikram K. Design and evaluation of matrix-based controlled-release tablets of diclofenac sodium and chondriotin sulphate. Am Assoc Pharm Sci 2007;8:88-97.

34. Basak SC, Jayakumar Reddy BM, Lucas Mani KP. Formulation and release behaviour of sustained-release ambroxol hydrochloride HPMC matrix tablet. Indian J Pharm Sci 2006;6:594-7.

35. Bhalla HL, Handa AK. Development and evaluation of controlled release tablets of carbamazepine. Indian Drugs 1999;4:100-5.

36. Chien YW. Controlled and modulated-release drug delivery systems. In: Swarbrick J, Balyan JC. Encyclopedia of pharmaceutical technology. New York: Marcel Dekker; 1990;2:281-313.

37. Ghugarkar P, Swain K, Suggala V, Adsare P, Shaik P. Review on bilayer tablet technology. World J Pharm Res 2009;4:1434-52.

38. Rashmin N, Praful D. Formulation and evaluation of dualcomponent tablets of metoprolol tartrate. Int J Pharm Chem Sci 2012;1:514-22.

39. Banerjee ND, Singh SR. Formulation and evaluation of compression coated tablets of cefpodoxime proxetil. Int J Pharma Sci Res 2013;4:104.

40. Atul K, Ashok KT, Narendra KJ, Subheet J. Formulation and in vitro in vivo evaluation of extended-release matrix tablet of zidovudine: influence of the combination of hydrophilic and hydrophobic matrix formers. Am Assoc Pharm Sci 2006;7:1-10. 